\title{
Arquitetura, anatomia e histoquímica das folhas de Gomphrena arborescens L.f. (Amaranthaceae) ${ }^{1}$
}

\author{
Suzane Margaret Fank-de-Carvalho ${ }^{2,3}$ e Dalva Graciano-Ribeiro ${ }^{2}$
}

Recebido em 11/05/2004. Aceito em 19/10/2004

\begin{abstract}
RESUMO - (Arquitetura, anatomia e histoquímica das folhas de Gomphrena arborescens L.f. (Amaranthaceae)). As folhas de Gomphrena arborescens L.f., nativa do Cerrado, são utilizadas contra dismenorréia na medicina popular. As investigações morfológica, anatômica e histoquímica das folhas visam fornecer elementos para taxonomia, para controle de qualidade de drogas e identificação microscópica de fitoterápicos. Folhas foram coletadas em Brasília, DF, nas áreas de Cerrado do Centro Olímpico da Univesidade de Brasília e na Reserva Ecológica do IBGE. Foram efetuadas análises morfológicas, anatômicas e histoquímicas. Os estudos de arquitetura foliar, densidade estomática e de vênulas terminais foram efetuados em folhas diafanizadas, apresentando médias de 42,39 $\pm 15,50$ estômatos mm ${ }^{-2}$ e $11,7 \pm 3,55$ vênulas terminais $\mathrm{mm}^{-2}$. As folhas apresentaram duas formas de tricomas tectores. O mesofilo bilateral apresenta tecido clorenquimático disposto radialmente à bainha parenquimática completa que envolve os feixes vasculares, características da síndrome Kranz associada ao ciclo fotossintético $\mathrm{C}_{4}$. $\mathrm{O}$ amido concentra-se na bainha parenquimática. As folhas são ricas em celulose, drusas de oxalato de cálcio, proteínas, lignina e outros compostos fenólicos, entre eles os flavonóides. As folhas apresentam morfologia variável, mas o padrão anatômico e de venação são constantes.
\end{abstract}

Palavras-chave: Gomphrena arborescens, arquitetura foliar, síndrome Kranz, compostos fenólicos, flavonóides

\begin{abstract}
Architecture, anatomy and histochemistry of the leaves of Gomphrena arborescens L.f. (Amaranthaceae)). Leaves of the Brazilian Cerrado plant Gomphrena arborescens L.f. are used against dismenorea in popular medicine. The morphological, anatomical and histochemical investigation aims to help taxonomy, quality control of drugs and microscopical identification of phytotherapics. The leaves have been collected in Brasília, DF, in the Olympical Center of the University of Brasilia and in the Ecological Reserve of IBGE. The leaf architecture, stomatal and veinlet densities have been studied in clarified leaves, presenting average of $42,39 \pm 15,50$ stomata mm $^{-2}$ and 11,7 $\pm 3,55$ veinlet $\mathrm{mm}^{-2}$. Leaves presented two forms of tector trichomes. The bilateral mesophyll surrounds the complete bundle sheat, features of the Kranz syndrome associated with $\mathrm{C}_{4}$ photosynthetic pathway. The starch is concentrated in the bundle sheat cells. Leaves are rich in cellulose, calcium oxalate druses, proteins, lignin and other phenolic compounds, such as flavonoids. Leaves present variable morphology, but steady pattern of anatomy and veination.
\end{abstract}

Key words: Gomphrena arborescens, leaf architecture, Kranz syndrome, phenolic compounds, flavonoids

\section{Introdução}

A espécie Gomphrena arborescens L.f. (Amaranthaceae) é um subarbusto nativo dos campos cerrados e campos rupestres do Cerrado. Ocorre nos Estados de Mato Grosso, Mato Grosso do Sul, Goiás, Minas Gerais, São Paulo e no Distrito Federal (Siqueira 1992; Lorenzi \& Matos 2002). A planta é conhecida na medicina popular como paratudo, perpétua do mato, paratudinho e raiz-do-padre-salerma (Barros 1982; Pio Corrêa 1984; Siqueira 1987; 1992; 2002; Lorenzi \& Matos 2002). Sua floração ocorre entre novembro e abril, com pico em janeiro (Almeida et al. 1998; Proença et al. 2000). Devido a seus grandes e vistosos capítulos vermelhos, pode ter exploração econômica como planta ornamental (Lorenzi \& Matos 2002) e sofre intensa coleta para confecção de arranjos ornamentais secos (Salles \& Lima 1990).

Barros (1982) informou sobre a utilização das raízes de G. arborescens L.f., no Distrito Federal, em garrafadas no combate à febre, asma e bronquite. De acordo com Pio Corrêa (1984) e Almeida et al. (1998), a raiz da espécie é amarga, aromática, excitante, tônica e febrífuga, útil na debilidade geral. Além disso, suas folhas são utilizadas contra dismenorréia (Siqueira 1992), fator determinante para a escolha das mesmas como objeto de estudo, fundamentando-se em uma abordagem etnofarmacológica (Maciel et al. 2002).

De acordo com Borsch et al. (2001), membros da família Amaranthaceae sensu lato (incluindo

\footnotetext{
1 Parte da Dissertação de Mestrado da primeira Autora

2 Universidade de Brasília, Departamento de Botânica, C. Postal 04.457, CEP 70910-970, Brasília, DF, Brasil

3 Autor para correspondência: suzifank@unb.br
} 
Chenopodiaceae) são dominantes em ecossistemas áridos e semi-áridos e apresentam uma série de características e estratégias (fotossíntese $\mathrm{C}_{4}$, sistemas reprodutivos especializados, morfologia e anatomia peculiares) que permitem que sobrevivam em diferentes hábitats e nas condições ambientais mais desfavoráveis, além de ser considerado o grupo tradicional para o estudo da via fotossintética $\mathrm{C}_{4}$, entre as dicotiledôneas.

No Brasil ocorrem 46 espécies do gênero Gomphrena e 19 delas ocorrem no Cerrado (Siqueira 1984; 1992). Seis espécies de Gomphrena são usadas na medicina popular - G. arborescens, G. globosa, G. leucocephala, G. pohlii, G. vaga e G. mollis - a maioria contra infecções nas vias respiratórias e como febrífugas ou tônicas, com utilização, principalmente, das raízes (Siqueira 1987). De acordo com pesquisadores da organização ambientalista WWF (BBC 2004), o consumo desenfreado de espécies medicinais pode levar à extinção, no ambiente, de aproximadamente $20 \%$ das ervas medicinais conhecidas.

Carolin et al. (1978) descreveram a síndrome Kranz encontrada em folhas de membros da família Amaranthaceae, entre eles espécies do gênero Gomphrena, e associaram sua ultra-estrutura à fotossíntese $\mathrm{C}_{4}$. Espécies desse gênero, ocorrentes no Cerrado, têm sido objeto de estudos de morfologia polínica (Laboriau 1961), de morfologia e anatomia foliar (Handro 1964), de ultra-estrutura foliar (EstelitaTeixeira \& Handro 1984), de vascularização floral (Monteiro-Scanavacca 1971) e de taxonomia (Siqueira 1992). Além disso, G. officinalis Mart. (=G. arborescens L.f.) foi investigada quanto à capacidade de inibição do carcinoma de Ehrlich por Rosito et al. (1971).

Calixto (2001) ressaltou que as pesquisas para desenvolvimento de medicamentos são demoradas e dispendiosas e que a Organização Mundial de Saúde estimula o uso de plantas medicinais pela população de países pobres. Deve ser considerada, no uso das plantas medicinais, a garantia da eficácia e segurança do uso de tais drogas; entre as providências, evitar efeitos colaterais que podem decorrer de fatores extrínsecos ao medicamento, como a falta da identificação correta da planta e a ausência de padronização e de controle de qualidade do produto (Silva et al. 1976; Calixto 2001).

A Agência Nacional de Vigilância Sanitária, por meio da resolução RDC 17, de 24/fevereiro/2000, estabeleceu que a solicitação do registro de um produto fitoterápico só ocorre mediante, entre outros documentos, a identificação botânica oficial da planta que compõe a matéria prima de origem, bem como de um laudo de identificação macro e microscópica do órgão vegetal utilizado, emitido por profissional habilitado (ANVISA 2000).

Este trabalho visa a descrição foliar para permitir a identificação de G. arborescens em estádio vegetativo, especialmente em locais onde ocorrem outras espécies do mesmo gênero. As informações estruturais obtidas nesse estudo poderão auxiliar na caracterização ecofisiológica da espécie e fornecerão elementos para a identificação macro e microscópica de fitoterápicos produzidos a partir desse órgão vegetal. Além disso, os resultados dos testes histoquímicos servirão como elementos de comparação qualitativa para identificação de drogas fitoterápicas e para a prospecção do(s) princípio(s) ativo(s) do vegetal.

\section{Material e métodos}

Para os estudos morfológicos e anatômicos foram utilizadas folhas adultas ( $2^{\circ}$ a $4^{\circ}$ nó) de sete plantas, coletadas no Centro Olímpico da Universidade de Brasília e na Reserva Ecológica do IBGE, em Brasília, $\mathrm{DF}$, ambas áreas de Cerrado sensu strito. As folhas foram fixadas em FAA ou FPA e conservadas em etanol $70 \%$ até o processamento (Kraus \& Arduin 1997).

Para a diafanização das folhas foi utilizada a técnica de Shobe \& Lersten, 1967 (apud Kraus \& Arduin 1997), com montagem integral das folhas entre duas placas de vidro, em resina sintética Entellan ${ }^{\circledR}$ ou verniz para artesanato (técnica em desenvolvimento). Parcelas das folhas foram montadas entre lâmina e lamínula. As lâminas de folhas inteiras foram ampliadas em papel fotográfico preto e branco, usando a lâmina como positivo para a geração da imagem em negativo no papel. A arquitetura foliar foi descrita de acordo com padrões preconizados por Hickey $(1974 ; 1979)$.

Para estudos anatômicos, parte das folhas fixadas foi cortada a mão livre e parte seguiu rotina de emblocamento em parafina, com a realização de cortes seriados em micrótomo rotatório Leica RM-4125, dupla coloração com safranina e verde firme e montagem entre lâmina e lamínula com a resina sintética, de acordo com Kraus \& Arduin (1997).

Partes das folhas foram submetidas à solução de Franklin e mantidas em estufa $40^{\circ} \mathrm{C}$ até a dissociação das células. A solução foi filtrada em tecido sintético durante seis lavagens em água destilada e a suspensão foi submetida ao corante aquoso azul de astra-safranina $(1: 1 \mathrm{v} / \mathrm{v})$ e montadas entre lâmina e lamínula com 
gelatina glicerinada de Kaiser (Kraus \& Arduin 1997).

A quantidade de estômatos por milímetro quadrado foi estabelecida de acordo com Laboriau et al. (1961), por meio de contagens em seis folhas adultas diafanizadas, de três plantas diferentes, sob microscópio óptico Zeiss Axiophot equipado com câmara-clara. Foram contadas nove áreas aleatórias de 0,476 mm² por superfície por folha, sendo três na região basal, três no terço médio e três no ápice, perfazendo 54 áreas para cada face foliar. O número de vênulas terminais por milímetro quadrado foi estabelecido por meio de uma adaptação da mesma técnica; de acordo com Metcalfe \& Chalk (1979), este é um importante dado auxiliar com propósito de diagnóstico para farmacognosia.

Para a determinação da espessura foliar e do comprimento dos tricomas curtos, foram efetuadas 25 medições em diferentes cortes transversais, no terço médio de folhas de três indivíduos, sob microscópio óptico com ocular milimetrada, de acordo com Paula \& Alves (1997). A mesma técnica foi utilizada em folhas diafanizadas para estabelecer as dimensões dos estômatos e das células basais dos tricomas longos e curtos. O comprimento dos tricomas longos foi obtido por meio de 25 medições dos tricomas integrais em raspagens epidérmicas montadas entre lâmina e lamínula (Theobald et al. 1979).

Todas as medidas realizadas estão expressas em valores médios, acompanhados dos respectivos desvios-padrão.

Para os estudos de histoquímica foram utilizadas folhas adultas frescas, coletadas de uma planta ocorrente no Centro Olímpico da Universidade de Brasília (Brasília, DF). Os cortes a mão livre foram submetidos a diferentes corantes e reagentes. De acordo com Kraus \& Arduin (1997), os testes usados nos estudos anatômicos para o reconhecimento de metabólitos celulares, em geral, reagem a mais de uma substância, gerando a necessidade de testes complementares, com controle, para garantir correta interpretação. Em razão dessa recomendação, foram realizados um a três testes para cada substância, sendo considerados como passíveis de testes complementares aqueles compostos determinadas por apenas uma reação de coloração.

Os testes realizados de acordo com Kraus \& Arduin (1997) foram: lugol seguido de ácido sulfúrico e cloreto de zinco iodado para paredes celulósicas; solução aquosa de vermelho de rutênio 0,02\% para substâncias pécticas; ácidos acético glacial, clorídrico $10 \%$ e sulfúrico $10 \%$ para a composição química das drusas; sudan IV etanólico para compostos graxos de cadeia longa (cutina, suberina e outros lipídios); teste de Fehling para açúcares redutores e hidrólise com ácido clorídrico 5\% para sacarose; lugol e cloreto de zinco iodado para amido e lignina; floroglucina ácida e Steinmetz-Costa para paredes lignificadas e/ou suberificadas.

De acordo com Johansen (1940) os testes foram: solução de acetato cúprico aquoso a 7\% para resinas; solução saturada aquosa de ácido pícrico por 24 h e reação conjugada às soluções aquosas de ferrocianeto de potássio seguida de cloreto férrico $5 \%$ para corpos protéicos; acetona por 18 h seguida de sudan IV etanólico para lecitinas; etanol 70\% por uma semana seguido timol etanólico a 15\% e ácido sulfúrico concentrado para frutanos e observação sob luz polarizada; fixação em solução aquosa de formalina $5 \%$ e sulfato ferroso $10 \%$ e reação ao cloreto de ferro aquoso a $10 \%$ com bicarbonato para compostos fenólicos; extração de alcalóides com ácido tartárico $5 \%$ em etanol $95 \%$ por uma semana, para controle de reações; ácido sulfúrico concentrado para saponinas e lactonas sesquiterpênicas.

Além dos testes acima, para a caracterização dos compostos fenólicos gerais, foi realizado o teste com solução aquosa de dicromato de potássio a 10\% (Gabe 1968). Para evidenciar os flavonóides através dos fluorocromos sob luz UV, foram realizados os testes com acetato de chumbo 3\%, cloreto de alumínio 15\% e reagente de Wilson (Charrière-Ladreix 1976). Para evidenciar taninos, teste com vanilina clorídrica 0,5\% em ácido clorídrico a 9\% (Mace \& Howell 1974). Para a detecção de alcalóides, foram utilizados os reagentes de Ditmar, Ellram e Wagner (Furr \& Mahlberg 1981), em cortes sem tratamento prévio e em cortes submetidos ao ácido tartárico etanólico (Johansen 1940).

As estruturas anatômicas e reações histoquímicas foram analisadas e fotografadas nos microscópios Olympus BX-40, equipado com fluorescência (Laboratório de Anatomia Vegetal da UnB), e Zeiss Axiophot, equipado com luz polarizada (Laboratório de Microscopia Eletrônica da UnB), ambos com máquinas fotográficas acopladas.

\section{Resultados}

Arquitetura foliar - As folhas de G. arborescens são sésseis, simples e inteiras, de textura coriácea e a filotaxia é, geralmente, oposta cruzada. As folhas têm ápices mucronados, margens inteiras e não apresentam glândulas no limbo (Fig. 1A). Tricomas tectores 
multicelulares não-ramificados recobrem toda a epiderme. A forma varia entre elíptica, estreito-obovada e oblonga. O tamanho variou entre 7-11 cm compr. e 3,5-5,3 cm larg.

As folhas são peninérvias, camptódromas do tipo broquidódroma e com nervura primária de orientação reta e de tamanho forte a massivo. Quatro a sete pares de nervuras secundárias originam-se alternadamente, divergindo gradualmente em ângulos entre agudo e reto e inclinando-se exmedialmente (Fig. 1A). Da base para o ápice, a divergência das nervuras secundárias ocorre em ângulo entre $15-20^{\circ}$ (agudo reduzido) e atinge um ângulo máximo de divergência entre $55-60^{\circ}$; nas regiões mediana e apical, a divergência ocorre diretamente em ângulo agudo moderado (entre 75-90), com menor inclinação em direção ao ápice (Fig. 1B). Na região apical, os arcos secundários são formados em ângulos entre agudo amplo a reto e com percurso abruptamente curvado (Fig. 1C). Nervações intersecundárias compostas originam-se exmedialmente, em ângulo entre reto e obtuso (Fig. 1A).

As veias terciárias originam-se em ângulo predominantemente reto; na base foliar, um par diverge em ângulo agudo (Fig. 1A). As veias terciárias apresentam padrão oblíquo e disposição densa, predominantemente alterna (Fig. 1B). O modelo de venação é percorrente, com desenho sinuoso e recurvado. Arcos formados por nervuras de terceira e quarta ordens delineam a venação última marginal areolada a partir da porção mediana inferior da folha até o ápice (Fig. 1C). Na região basal, vênulas terminando livremente tornam a nervura última marginal e o padrão de areolação incompletos (Fig. 1D).

As aréolas são irregulares na forma e no tamanho, tendendo a ser maiores próximas à base foliar e reduzindo-se em direção ao ápice (Fig. 1A). Arcos encerram as veias secundárias, formando aréolas admediais de formato irregular e tamanho mediano a grande (Fig. 1B). As nervações de terceira e quarta ordens também formam aréolas, principalmente na porção mediana e apical, com disposição ao acaso (Fig. 1B). As nervações maiores formam, raramente, aréolas sem vênulas ou com vênulas simples (lineares ou curvadas); vênulas ramificadas, de uma a três vezes, são as mais freqüentes (Fig. 1B). São encontradas, em todas as regiões do limbo, aréolas obliteradas, isoladas do restante da nervação (Fig. 1E) ou conectadas à nervura adjacente por apenas uma célula da bainha parenquimática (Fig. 1F).

Anatomia foliar - Em vista paradérmica, as células epidérmicas comuns são tetra a poligonais, com ângulos arredondados, apresentando paredes anticlinais retas ou levemente sinuosas na face adaxial (Fig. 2A) e com maior sinuosidade na face abaxial (Fig. 2B). As células epidérmicas são alongadas sobre a nervura principal e nervuras secundárias e na região do bordo (Fig. 2C).

As folhas são anfiestomáticas, apresentando densidade média geral de 42,39₫15,50 estômatos por milímetro quadrado. Na face adaxial há uma média de $44,47 \pm 16,46$ estômatos por $\mathrm{mm}^{2}$ e, na face abaxial, 40,31 $\pm 14,33$ estômatos $\mathrm{mm}^{-2}$.

Os estômatos são, principalmente, anomocíticos. Estão localizados entre as nervuras e nas proximidades das mesmas, orientados ao acaso e circundados por 3-5 células epidérmicas comuns (Fig. 2A-B, D). As células-guarda reniformes têm comprimento

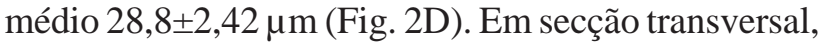
os estômatos aparecem nivelados ou levemente elevados, geralmente mais salientes na face abaxial. As células-guarda apresentam as paredes periclinais interna e externa mais espessas em relação às anticlinais. A partir das paredes periclinais externas, pequenas cristas projetam-se para superfície, configurando um átrio externo durante a abertura dos ostíolos (Fig. 2E).

Em vista paradérmica de folhas diafanizadas, os feixes vasculares apresentam-se envolvidos por uma bainha de células parenquimáticas normalmente lignificadas, com células isodiamétricas a alongadas. As nervuras terminam em 1-3 traqueídeos, longos ou curtos, normalmente paralelos entre si, da mesma forma que são encontrados nas aréolas obliteradas; as paredes primárias apresentam reforço helicoidal de parede secundária (Fig. 2F). Em média, há 11,8 $\pm 3,4$ vênulas terminais por milímetro quadrado.

O indumento das folhas de G. arborescens é espesso. Os tricomas tectores longos são pluricelulares (4-12 células), unisseriados e não-ramificados (Fig. 3 A-B). As células próximas à epiderme são curtas e largas, translúcidas sob lupa (Fig. 3A); as células intermediárias, alongadas, são ferrugíneas e têm formato osteolado (Fig. 3B); a célula apical é acuminada e incolor; todas as paredes celulares são espessas. O comprimento médio desses tricomas é de 3,06 $\pm 0,88 \mathrm{~mm}$ (Fig. 3A). Projeções digitiformes nas paredes periclinais formam nódulos articulados entre células vizinhas (Fig. 3B); as pequenas protuberâncias das paredes anticlinais, sob luz polarizada, representam projeções ectoplasmáticas através de pontoações (Fig. 3B). Em vista paradérmica, a célula basal dos tricomas longos é arredondada, com diâmetro médio

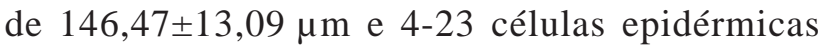



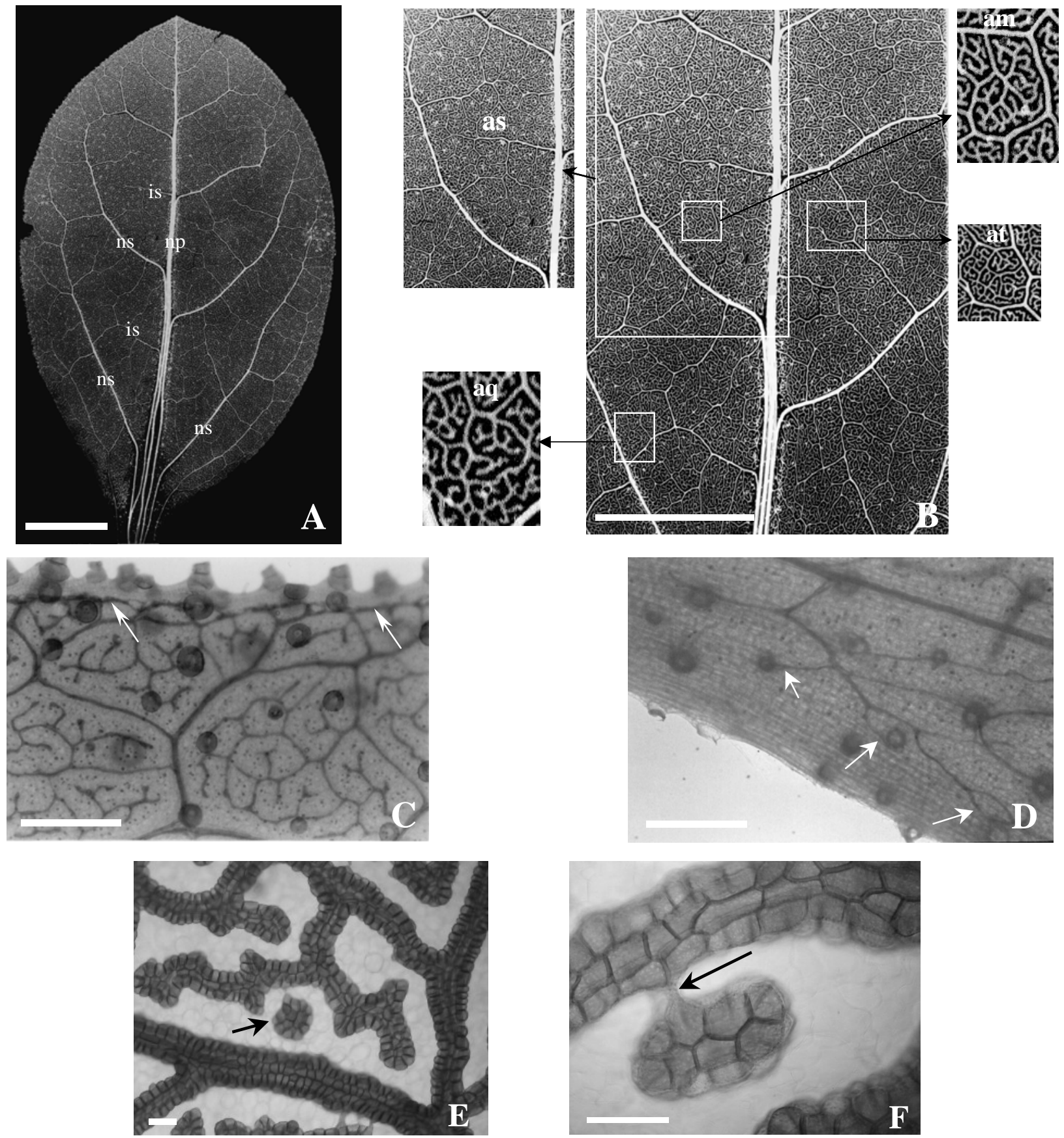

Figura 1. Folhas diafanizadas de Gomphrena arborescens L.f. A-B. Ampliação como negativo sobre papel fotográfico P\&B; barra = $1 \mathrm{~cm}$. C-F. Barra $=100 \mu \mathrm{m}$. A. folha simples, pinada, camptódroma do tipo broquidódroma, com a nervura primária (np) de orientação reta, de tamanho forte a massivo. Seis pares de nervuras secundárias (ns) originam-se alternadamente e em ângulos variando entre agudo e reto. Nervação intersecundária (is) composta, conecta as nervuras primária e secundária através de veias de terceira ordem, em percurso sinuoso. B. detalhes da folha no terço médio: (as) = aréola secundária, dentro das quais se inserem aréolas formadas por nervuras de terceira e quarta ordens; $($ at) = aréola terciária; $(\mathrm{am})$ = aréola terciária e quaternária; $(\mathrm{aq})$ = aréola quaternária com os diferentes tipos de vênulas terminais. C. Nervação última marginal (setas), areolada, formada pelos arcos de ordens maiores. D. Vênulas terminando livremente, na base da folha (setas), região do bordo, com nervura última marginal incompleta. E. Aréola obliterada, isolada (seta). F. Aréola obliterada conectada à nervura adjacente através das células da bainha parenquimática (seta). 
adjacentes, normalmente lignificadas, estão dispostas radialmente (Fig. 3C).

Os tricomas tectores curtos também são pluricelulares (8-14 células), unisseriados e nãoramificados, inteiramente translúcidos sob lupa (Fig.
3A). As 4-5 células da base apresentam leve espessamento de parede e lignificação e as demais células alongam-se em direção ao ápice acuminado, sendo freqüente a presença de células intermediárias com paredes colapsadas (Fig. 3D). Freqüentemente,
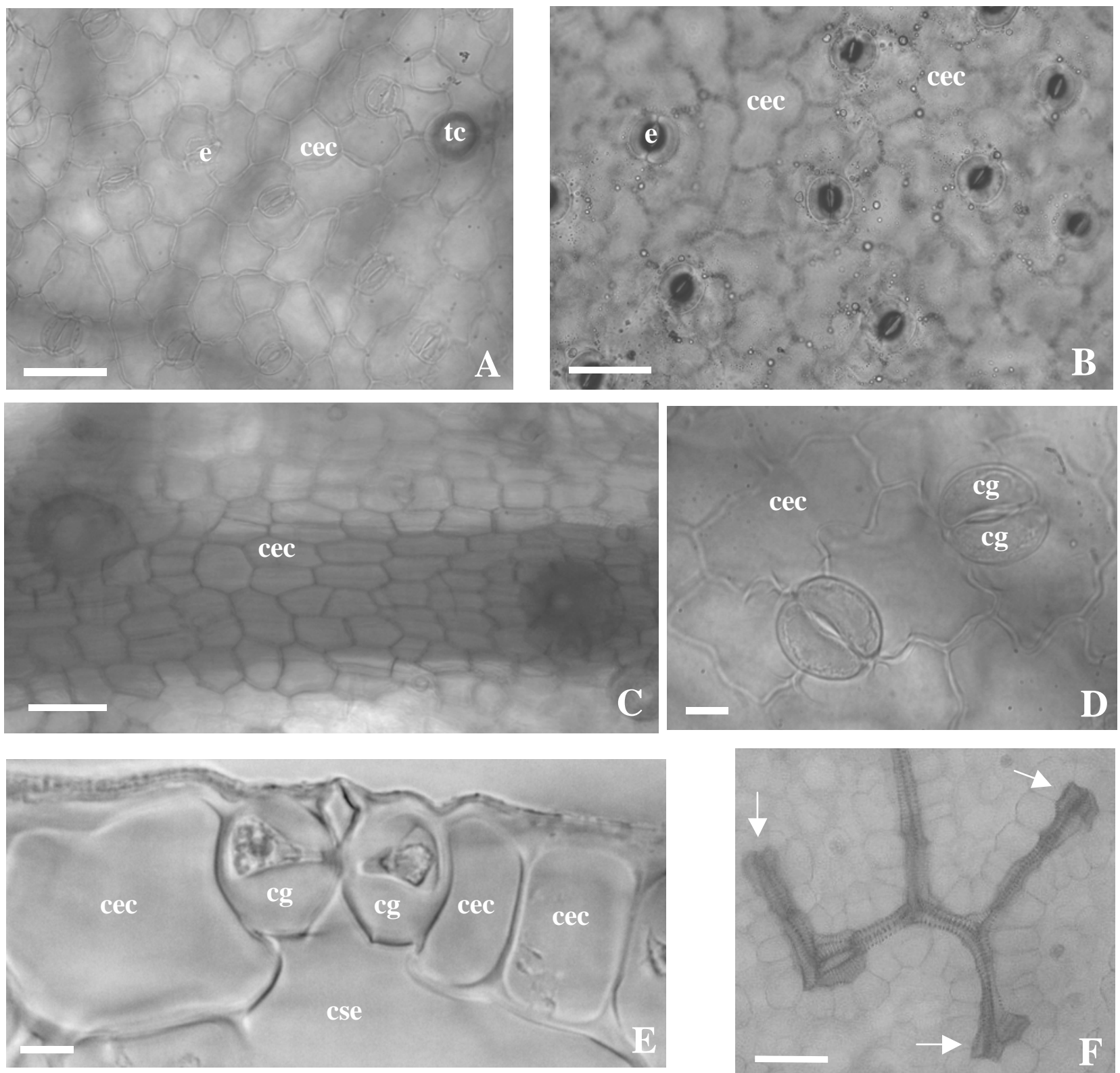

Figura 2. Folhas diafanizadas de Gomphrena arborescens L.f. em vista paradérmica (A-D, F) e transversal (E), sob microscópio óptico. A. Epiderme adaxial, mostrando a forma das células epidérmicas comuns (cec), a célula basal do tricoma curto (tc) e os estômatos (e). Barra $=50 \mu \mathrm{m}$. B. Epiderme abaxial, mostrando as paredes anticlinais mais sinuosas das células epidérmicas comuns (cec) e a disposição ao acaso dos estômatos (e). Barra = $50 \mu \mathrm{m}$. C. Células epidérmicas comuns (cec) alongadas sobre a nervura secundária na face abaxial, similar à forma das células epidérmicas comuns na nervura principal e no bordo. Barra $=100 \mu \mathrm{m}$. D. Estômatos com células-guarda (cg) reniformes e células epidérmicas comuns (cec) na face abaxial. Barra $=10 \mu \mathrm{m}$. E. Corte transversal, mostrando as células epidérmicas comuns (cec), células-guarda (cg) de um estômato fechado em corte equatorial e a câmara sub-estomática (cse). Barra = $5 \mu$ m. F. Traqueídeos (seta), com reforços helicoidais de paredes secundárias, encontrados nas vênulas terminais e nas aréolas obliteradas. Barra $=400 \mu \mathrm{m}$. 
as células intermediárias e apicais estão danificadas, provavelmente por fungos, podendo apresentar-se disformes. Em vista paradérmica, a célula basal é arredondada (Fig. 2A), com diâmetro similar ao de um

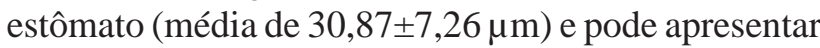
ou não células adjacentes em arranjo radial. Apresentando comprimento médio de 0,78 $\pm 0,18 \mathrm{~mm}$, esse tipo de tricoma não foi descrito anteriormente para a espécie.

Na secção transversal da região basal da folha é visível a formação em arco aberto do sistema vascular proveniente do traço foliar (Fig. 4A). A nervura primária e as secundárias apresentam-se salientes apenas na face abaxial.

A epiderme é unisseriada, com células tabulares e cutícula fina em ambas as superfícies foliares. $\mathrm{Na}$ nervura principal, as paredes das células epidérmicas apresentam-se igualmente espessadas e a cutícula apresenta estriações (Fig. 4B).

Há colênquima angular logo abaixo da epiderme em ambas as faces da nervura principal e do bordo, na região basal da folha. Na nervura principal, o colênquima apresenta 3 a 4 camadas na face adaxial e 1-2 camadas seguidas de mais 1-2 camadas de células parenquimáticas incolores com espessamentos na face abaxial (Fig. 4B). O colênquima não foi encontrado no bordo na região do terço médio e em nenhuma área na região apical.

O mesofilo apresenta simetria bilateral, com 1-2 camadas de parênquima paliçádico na face adaxial e 2-3 camadas de parênquima lacunoso na face abaxial (Fig. 4C). Na região do terço médio, entre a nervura principal e o bordo, a espessura foliar média é de $384,40 \pm 66,47 \mu \mathrm{m}$. Há maior concentração de clorofila nas células do parênquima clorofiliano em contato com a bainha parenquimática dos feixes vasculares.

O parênquima paliçádico ocorre em disposição variada em relação à bainha parenquimática vascular, podendo apresentar-se disposto perpendicularmente ou irradiando da mesma (Fig. 4C-D). Algumas células largas, com ausência ou reduzido número de cloroplastos, caracterizam um parênquima incolor descontínuo entre as células do parênquima paliçádico ou sob a epiderme (Fig. 4 C-D). Em geral, o parênquima incolor localiza-se nas regiões intervenais, próximas aos estômatos e sob as células dos tricomas longos. Nas regiões onde o parênquima incolor inicia a formação de uma camada subepidérmica, próximo aos tricomas longos, a disposição do parênquima paliçádico é tipicamente radial (Fig. 4D).

Na face abaxial, as células adjacentes à bainha são pequenas, com pequenos espaços intercelulares e em disposição radial em relação à bainha parenquimática (Fig. 4D). As demais camadas do parênquima lacunoso são grandes e lobadas.

Os feixes vasculares são colaterais e estão envolvidos por uma bainha parenquimática completa, simples, com células de paredes espessas e lignificadas, densamente pontoadas, com cloroplastos (Fig. 4C-D). Pela forma peculiar, essas células podem ser identificadas mesmo em tecidos macerados (Fig. 4E). $\mathrm{Na}$ nervura principal, que geralmente apresenta crescimento secundário, uma calota de fibras pericíclicas de lúmen amplo ocorre junto ao floema secundário (Fig. 4F). Nos tecidos macerados foram encontradas fibras longas e largas (provavelmente relacionadas ao floema) e fibras curtas e finas (provavelmente relacionadas ao xilema).

Drusas de oxalato de cálcio foram encontradas em grandes células idioblásticas arredondadas, isoladas ou em pequenos agrupamentos, distribuídas por todo o mesofilo.

Histoquímica - A cutícula é fina em ambas as faces das folhas, com maior impregnação de compostos graxos na face adaxial. Foram encontradas gotas de lipídios no citoplasma de células isoladas dos tecidos parenquimáticos (Tab. 1).

Algumas substâncias citoplasmáticas presentes nas células da epiderme adaxial e do parênquima paliçádico reagiram ao sudan IV etanólico; o mesmo teste efetuado após $18 \mathrm{~h}$ em acetona indica que nestas células encontram-se lecitinas - um grupo de compostos fosfolipídicos (Tab. 2).

As bainhas parenquimáticas das nervuras foliares de G. arborescens são lignificadas. Em termos gerais, a lignificação é mais evidente no terço médio e ápice foliar, em relação à base (Tab. 2).

Corpos protéicos foram encontrados no citoplasma da maioria das células, inclusive na região cambial da nervura principal, nas células apicais dos tricomas curtos e em algumas células basais dos tricomas longos. Os cloroplastos também apresentaram reação positiva para proteínas e a reação citoplasmática mais intensa ocorreu no interior das células da bainha parenquimática (Tab. 1).

O amido foi encontrado, principalmente, nas células da bainha parenquimática (Tab. 1). Os açúcares redutores foram evidenciados nas células do mesofilo em contato com a bainha parenquimática (Tab. 1). A sacarose foi encontrada nos mesmos tecidos, mas em menor proporção. Esferocristais de frutanos não foram encontrados nas folhas (Tab. 1). 
Os compostos fenólicos foram encontrados em quase todos os tecidos foliares, em diferentes concentrações (Tab. 2). Em termos gerais, impregnam a face externa da cutícula e as paredes das células intermediárias dos tricomas longos; precipitam-se no citoplasma de células intermediárias e apicais do tricoma curto, nas células basais do tricoma longo, nas células da epiderme adaxial, em células isoladas ou grupos de células do mesofilo, nas regiões centrífugas das células da bainha parenquimática e na região cambial da nervura principal. A existência de compostos fenólicos dentro das células da bainha parenquimática foi confirmada pela observação de cortes sem tratamento sob fluorescência em UV, onde apareceram em tons verde a verde-azulados.

Os taninos apareceram em células isoladas do mesofilo, claramente infectadas com hifas de fungos, e impregnando as paredes anticlinais das células intermediárias dos tricomas longos e a cutícula (Tab. 2).

Os flavonóides foram localizados na face externa da cutícula, especialmente na face adaxial, nas paredes das células basais e intermediárias dos tricomas curtos e longos, nas células-guarda e no mesofilo em contato com a bainha parenquimática (Tab. 2). A reação foi menos intensa nas paredes das células da bainha e demais células parenquimáticas do mesofilo, e não ocorreu no colênquima.
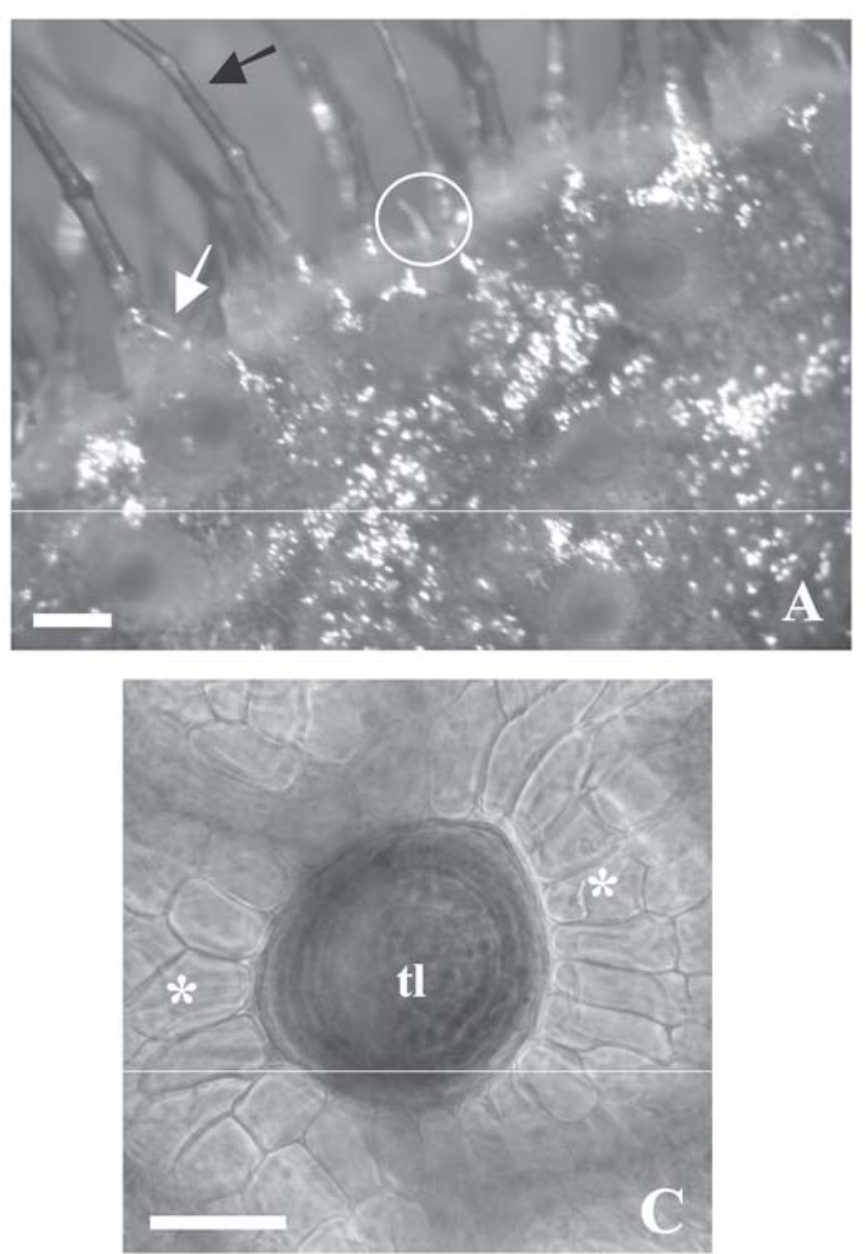
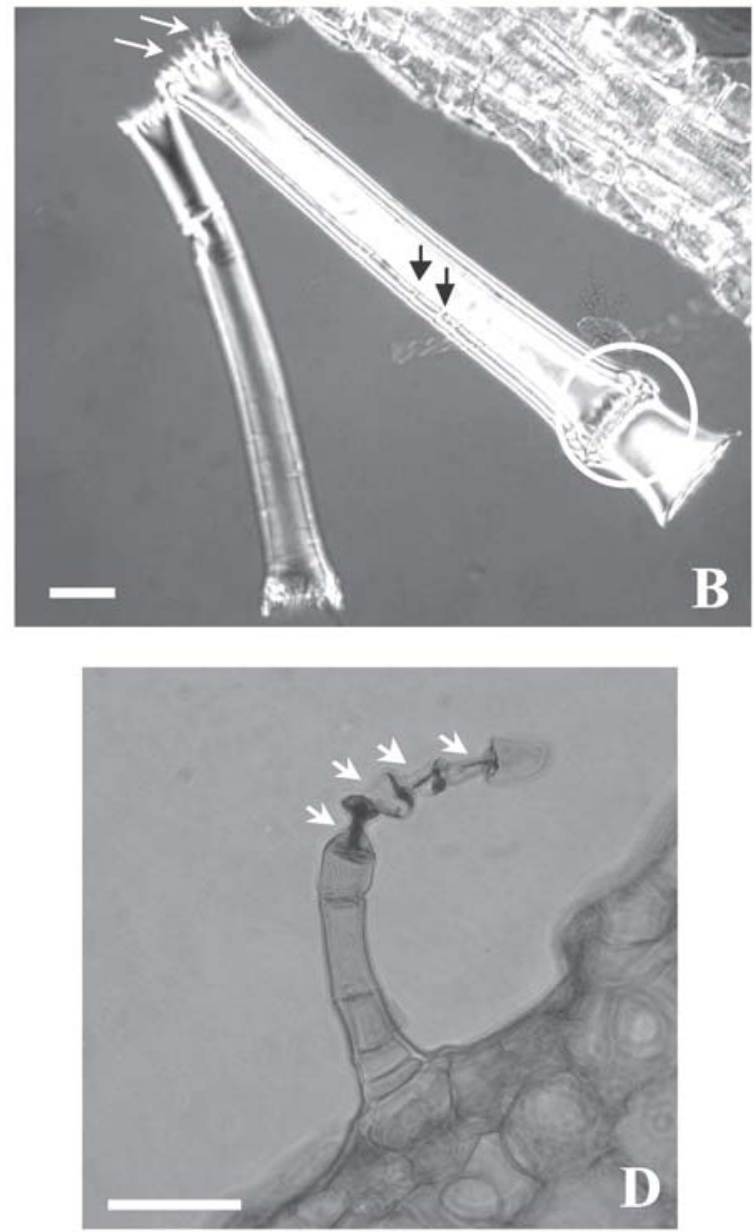

Figura 3. Detalhes da epiderme e dos tricomas das folhas de Gomphrena arborescens L.f., sob lupa (A) e sob microscópio óptico (B-D). A. Face adaxial na região do bordo, sem tratamento, aspectos gerais: célula intermediária do tricoma longo, de cor ferrugínea (seta negra); célula basal do tricoma longo, translúcida (seta branca); tricoma curto (círculo). Barra = $200 \mu \mathrm{m}$. B. Células intermediárias do tricoma longo, dissociadas e sob luz polarizada, mostrando as pontoações nas paredes anticlinais (setas negras) e as projeções digitiformes nas paredes periclinais (setas brancas); articulação nodosa formada pelas paredes periclinais das células do tricoma longo (círculo). Barra = $100 \mu \mathrm{m}$. C. Célula basal do tricoma longo (tl) em vista paradérmica e disposição radiada de suas células adjacentes (*). Barra = $100 \mu$ m. D. Tricoma curto em corte transversal de folha, com as paredes das células intermediárias colapsadas (setas). Barra = $50 \mu \mathrm{m}$. 

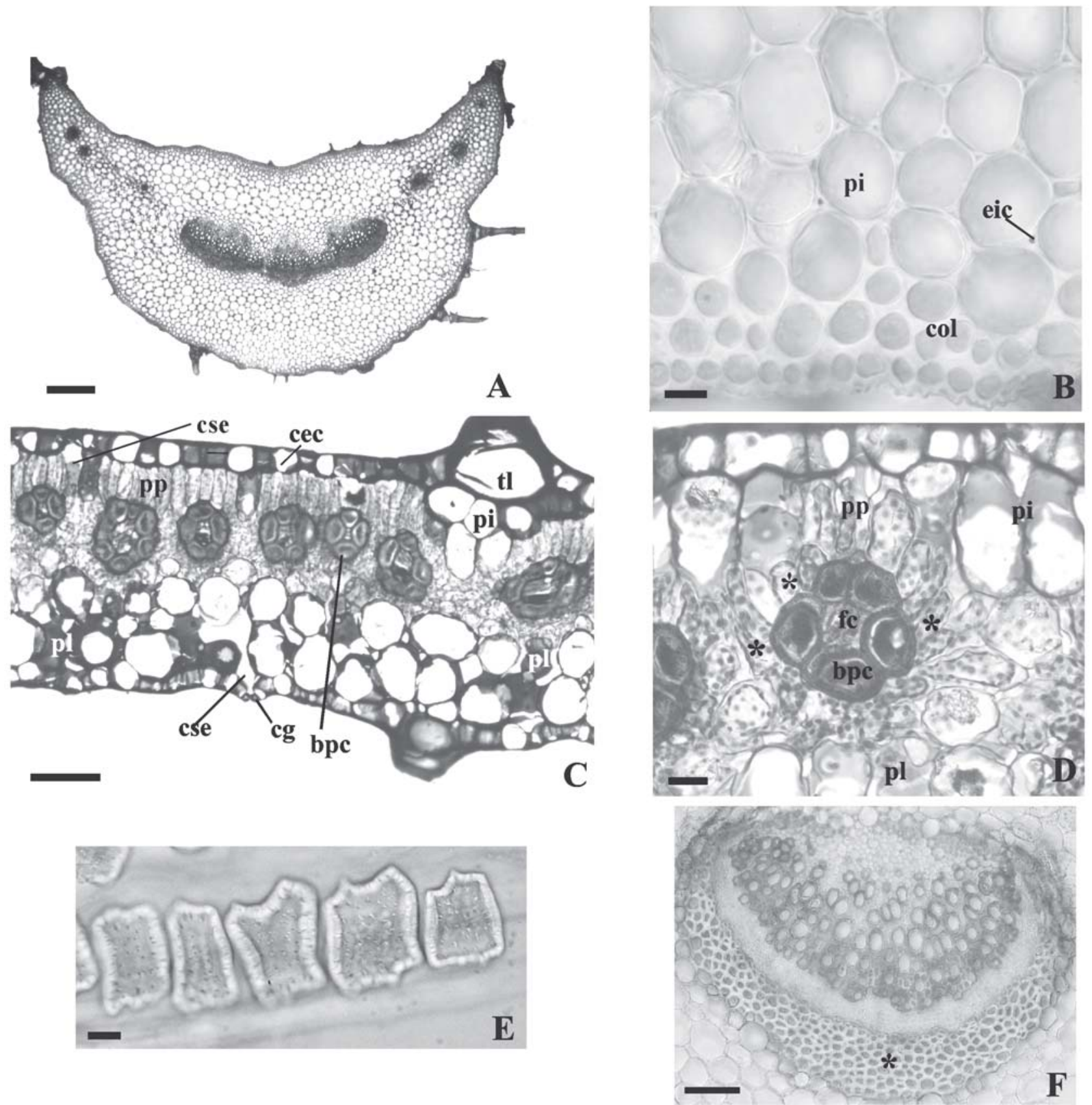

Figura 4. Secções transversais (A-D, F) e dissociado (E) de folha de Gomphrena arborescens L.f. A. Base séssil, com o sistema vascular em arco aberto. Barra $=500 \mu \mathrm{m}$. B. Face abaxial da nervura principal, na região basal, com cutícula estriada, epiderme de paredes espessadas, colênquima (col), parênquima incolor (pi) com espessamentos de parede e espaços intercelulares (eic). Barra = $100 \mu \mathrm{m}$. C. Simetria bilateral, na região do terço médio, com estômatos mais salientes na face abaxial (cg), câmara subestomática (cse), bainha parenquimática completa (bpc) envolvendo o feixe vascular, célula basal do tricoma longo (tl), parênquima incolor (pi), parênquima paliçádico (pp) e parênquima lacunoso (pl). Barra = $100 \mu \mathrm{m}$. D. Síndrome Kranz, com feixe colateral (fc) envolvido por uma bainha parenquimática completa (bpc), com células de paredes espessadas e lignificadas, parênquima paliçádico (pp) e lacunoso em disposição radiada (*), parênquima incolor (pi) e parênquima lacunoso (pl) de células grandes e lobadas. Barra $=25 \mu \mathrm{m}$. E. Células da bainha parenquimática sob luz polarizada. Barra $=50 \mu \mathrm{m}$. F. Feixe vascular da nervura principal, em crescimento secundário, com calota de fibras pericíclicas $(*)$ ocorrendo próximo ao floema secundário. Barra $=100 \mu \mathrm{m}$. 
Tabela 1. Localização de carboidratos, compostos graxos, proteínas e resinas em folhas de Gomphrena arborescens L.f., por meio de testes histoquímicos.

\begin{tabular}{|c|c|c|c|c|c|c|c|c|c|}
\hline \multirow[t]{2}{*}{ Tecido/estrutura anatômica } & \multicolumn{6}{|c|}{ Carboidratos } & \multirow{2}{*}{$\begin{array}{l}\text { Compostos graxos } \\
\text { de cadeia longa }\end{array}$} & \multirow[t]{2}{*}{ Proteínas } & \multirow[t]{2}{*}{ Resinas } \\
\hline & Amido & $\begin{array}{l}\text { Açúcares } \\
\text { redutores }\end{array}$ & Frutanos & Sacarose & Celulose & Pectinas & & & \\
\hline Tricomas longos & - & - & - & - & - & + & + & \pm & - \\
\hline Tricomas curtos & - & - & - & - & + & + & - & + & - \\
\hline Cutícula & - & \pm & - & \pm & - & + & ++ & - & - \\
\hline Células-guarda & + & - & - & - & + & + & + & + & - \\
\hline Células epidérmicas comuns & - & - & - & - & + & ++ & \pm & \pm & - \\
\hline Colênquima e parênquima incolor & - & \pm & - & \pm & ++ & ++ & + & + & - \\
\hline Feixes vasculares & - & \pm & - & \pm & + & ++ & + & + & - \\
\hline $\begin{array}{l}\text { Par paliçádico e lacunoso em contato } \\
\text { com a bainha parenquimática }\end{array}$ & \pm & ++ & - & + & ++ & ++ & \pm & ++ & - \\
\hline Bainha parenquimática & ++ & ++ & - & + & - & + & \pm & ++ & - \\
\hline $\begin{array}{l}\text { Parênquima lacunoso sem contato } \\
\text { com bainha parenquimática }\end{array}$ & \pm & + & - & \pm & ++ & ++ & \pm & + & - \\
\hline
\end{tabular}

- reação negativa para o composto; \pm reação em células isoladas e/ou que necessita de confirmação (pouco característica); + reação em grupos de células e/ou com intensidade mediana; ++ reação em todo o tecido e/ou com intensidade forte

Tabela 2. Localização de compostos secundários em folhas de Gomphrena arborescens L.f. por meio de testes histoquímicos.

\begin{tabular}{|c|c|c|c|c|c|c|c|c|}
\hline \multirow[t]{2}{*}{ Tecido/estrutura anatômica } & \multirow[t]{2}{*}{ Alcalóides } & \multicolumn{4}{|c|}{ Compostos fenólicos } & \multirow{2}{*}{$\begin{array}{c}\text { Lactonas } \\
\text { sesquiterpênicas }\end{array}$} & \multirow{2}{*}{ Lecitinas } & \multirow[t]{2}{*}{ Saponinas } \\
\hline & & Gerais & Flavonóides & Taninos & Lignina & & & \\
\hline Tricomas longos & - & ++ & ++ & + & ++ & - & - & - \\
\hline Tricomas curtos & - & + & ++ & \pm & + & - & - & - \\
\hline Cutícula & - & ++ & ++ & + & + & - & - & - \\
\hline Células-guarda & - & + & ++ & - & + & - & - & - \\
\hline Epiderme & - & \pm & - & - & + & - & ++ & - \\
\hline Colênquima e parênquima incolor & - & \pm & - & \pm & - & - & - & - \\
\hline Feixes vasculares & - & \pm & + & - & + & - & - & - \\
\hline $\begin{array}{l}\text { Par paliçádico e lacunoso em contato } \\
\text { com a bainha parenquimática }\end{array}$ & 0 & \pm & ++ & \pm & - & - & + & - \\
\hline Bainha parenquimática & - & + & \pm & - & ++ & \pm & - & \pm \\
\hline $\begin{array}{c}\text { Parênquima lacunoso sem contato } \\
\text { com bainha parenquimática }\end{array}$ & - & \pm & + & \pm & - & - & - & - \\
\hline
\end{tabular}

- reação negativa para o composto; \pm reação em células isoladas e/ou que necessita de confirmação (pouco característica); + reação em grupos de células e/ou com intensidade mediana; ++ reação em todo o tecido e/ou com intensidade forte

A reação dos tecidos submetidos ao ácido sulfúrico concentrado para a detecção de saponinas e/ou lactonas sesquiterpênicas nas folhas foi considerada não conclusiva (Tab. 2). Apenas as células da bainha parenquimática apresentaram seqüência de coloração similar ao esperado para tais compostos. O teste para localização de lecitinas também foi considerado não conclusivo (Tab. 2), embora a reação tenha sido significativa na epiderme e, principalmente, no parênquima paliçádico.

Não foram encontrados os precipitados característicos de resinas (Tab. 1), nem detectada a presença de alcalóides nas folhas de G. arborescens (Tab. 2).

\section{Discussão}

G. arborescens L.f. pode ser encontrada em estádio vegetativo a partir do início da estação chuvosa (entre setembro e novembro), apresentando filotaxia oposta cruzada, em geral. A filotaxia na região terminal do caule pode apresentar-se rosulada em estádio vegetativo ou oposta decussada próxima à base da inflorescência (a floração foi observada entre 
dezembro e abril). Os ramos aéreos podem ser simples (haste solitária) ou múltiplos (várias hastes emergem do sistema subterrâneo). As folhas e o caule são densamente pilosos e podem apresentar coloração predominantemente verde ou com tons vináceos no caule e nas nervuras principais das folhas.

A coloração avermelhada encontrada na espécie pode ser atribuída às betalaínas. Esses pigmentos nitrogenados, amarelos e vermelhos, estão restritos à ordem Caryophyllales e substituem as antocianinas da maioria das Angiospermas, podendo fazer parte do perianto (funcionando na atração de polinizadores) e do caule, folhas e frutos, provavelmente com função adicional de proteção contra raios ultra-violetas (Judd et al. 1999).

Embora as folhas possam apresentar as formas elíptica, estreito-obovada ou oblonga, o padrão de venação de $G$. arborescens L.f. é bastante conservativo e pode auxiliar no reconhecimento da espécie em estádio vegetativo. Os caracteres mais conservativos são: nervura primária de orientação retilínea que se projeta no ápice mucronado; seis a sete pares de nervuras secundárias mais proeminentes, originando-se alternadamente em ângulos variando entre agudo (região basal) e reto (região mediana a apical); nervuras secundárias com divergência gradual (acompanham a nervura primária antes de inclinarem exmedialmente) e afiladas na formação dos arcos na região apical. As aréolas obliteradas isoladas ao longo de todo o limbo foliar também são constantes.

De acordo com a padronização sugerida por Hickey (1974 e 1979), G. arborescens apresenta nervuras de até quatro ordens, pois as venações mais finas formam um retículo relativamente uniforme que não permite diferenciação de calibre entre as mesmas. Handro (1964) determinou para G. officinalis Mart. (=G. arborescens) a existência de nervuras de até quarta ordem e de outras venações de menor porte (até a sétima ou oitava ordens), baseado apenas na mudança de posição das veias derivadas, o que coincide com a análise atual.

A espécie em estudo tem folhas com espessura intermediária e estômatos com freqüência similar nas duas faces, o que pode proporcionar alta condutância foliar ao $\mathrm{CO}_{2}$. Parkhust (1978) associou a anfiestomia a plantas herbáceas com espessura foliar intermediária, entre 100-500 $\mu \mathrm{m}$; na maioria das vezes, a densidade estomática é aproximadamente igual em ambas superfícies foliares. O fenômeno é considerado uma adaptação para aumentar a condutância máxima foliar ao $\mathrm{CO}_{2}$ que, associada a altas taxas fotossintéticas, favoreceria o acúmulo de carbono durante períodos de disponibilidade de água (Parkhust 1978; Mott et al . 1982).

De hábito subarbustivo, as estruturas aéreas de G. arborescens emergem principalmente durante a estação de chuvas ou logo depois de queimadas, estabelecendo-se em ambientes de alta irradiância solar. Esse aspecto concorda com a assertiva de Mott et al. (1982), que citou que, entre os vegetais sujeitos a diferentes graus de insolação, as plantas anfiestomáticas se estabelecem com sucesso em ambientes de pleno-sol, como pioneiras na sucessão ecológica.

As folhas de $G$. arborescens apresentam estômatos de tamanho mediano e dimensões pouco variáveis. O estabelecimento das dimensões dos estômatos pode ter valor diagnóstico quando o espectro de variação do tamanho é restrito (Wilkinson 1979); desta forma, esse caracter de G. arborescens pode ser considerado útil para auxiliar na diagnose e controle de qualidade de fitoterápicos baseados em folhas.

A densidade estomática das folhas de G. arborescens é relativamente baixa; os estômatos ocorrem entre as nervuras e principalmente, próximo às mesmas. De acordo com Wilkinson (1979), o tamanho e a densidade dos estômatos estão relacionados com as condições climáticas: as condições secas e/ou de pleno sol tendem a produzir estômatos maiores; estômatos muito grandes (acima de $38 \mu \mathrm{m}$ compr.) tendem a ocorrer sobre as nervações ou adjacentes a elas; plantas hidrófitas ou especialmente adaptadas a armazenar água podem apresentar estômatos médios a grandes, normalmente com baixa densidade; as freqüências estomáticas mais altas ocorrem em xerófitas (2200-2230 estômatos por mm²). A dimensão dos estômatos de G. arborescens pode estar relacionada à capacidade de armazenamento de água em suas estruturas subterrâneas e/ou às condições úmidas sazonais do hábitat durante a persistência do sistema aéreo (estação chuvosa).

$O$ indumento denso de $G$. arborescens poderia relacionar a espécie a um ambiente seco, especialmente pelas características dos tricomas longos. Muitos autores consideram a pubescência mais densa nos ambientes secos, relacionando-os à economia de água, seja pelo aumento da refletância da radiação solar ou pelo aumento da espessura da camada limítrofe de ar; em poucos e recentes estudos, os tricomas são também considerados barreiras físicas para redução de herbivoria (Ehrleringer 1984; Press 1999). De acordo com Gutschick (1999), além de afetar as trocas gasosas e a temperatura, os tricomas podem gerar prejuízos 
pelo decréscimo da interceptação da luz. A presença de grandes células vivas e translúcidas na base dos tricomas longos de G. arborescens, as características das células epidérmicas e do parênquima incolor subjacente e a organização do mesofilo parecem adaptações da espécie para reduzir o custo do indumento na interceptação da luz e à otimização do aproveitamento da irradiância solar. O nível de saturação da luz e a manutenção de uma temperatura foliar ótima, bem como o eventual efeito dos tricomas longos na herbivoria e nas trocas gasosas exigem investigações mais específicas.

As folhas de G. arborescens apresentam características escleromórficas. Entre elas: abundância de tricomas, de esclerênquima, de celulose e de lignina; nervuras densas e bem desenvolvidas e redução do número de folhas (em geral, 5-10 pares de folhas por haste). As folhas possuem, também, características de plantas mesomórficas ou hidromórficas: folhas amplas, células epidérmicas bem desenvolvidas, baixa densidade estomática e mesofilo de simetria bilateral. De acordo com Arens (1958), a escleromorfia pode ocorrer como conseqüência de atividade fotossintética elevada conjugada a fatores de restrição do crescimento, com o excesso de carbono fixado sendo convertido em estruturas escleromorfas. No caso de G. arborescens, as estruturas escleromorfas das folhas podem estar relacionadas a uma certa proteção contra herbivoria ou patógenos durante o curto ciclo de vida do sistema aéreo, à economia de água e à sustentação estrutural.

O padrão radial do mesofilo e a presença de uma bainha parenquimática completa, bem como a distribuição de amido nas folhas de G. arborescens é similar ao das espécies de Gomphrena descritas por Carolin et al. (1978); esse fato, juntamente com os demais caracteres anatômicos, predispõem a espécie para a realização da via fotossintética $\mathrm{C}_{4}$. Os estudos ultraestrutural e bioquímico podem auxiliar na correta determinação da via fotossintética e do subtipo predominante para a mesma.

Carolin et al. (1978) descreveram a ultra-estrutura de membros da família Amaranthaceae portadores da síndrome Kranz, entre eles as espécies Gomphrena celosioides, G. globosa, G. conica, G. brachystylis, G. brownii, G. flaccida e G. canescens e associaram sua ultra-estrutura à fotossíntese $\mathrm{C}_{4}$; entre essas espécies já havia sido determinada a fotossíntese $\mathrm{C}_{4}$ subtipo NADP-ME - em G. celosioides e G. globosa, por meio de estudos enzimáticos. Estelita-Teixeira \& Handro (1984) indicaram, através de estudo ultraestrutural, que a distribuição de diferentes tipos de cloroplastos nas folhas de Gomphrena macrocephala, G. prostrata e G. decipiens, nativas do Cerrado, é característica para a ocorrência da via fotossintética $\mathrm{C}_{4}$, subtipo NADP-ME.

Welkie \& Caldwell (1970) reportaram, por meio de estudos do ponto de compensação de dióxido de carbono em várias espécies de dicotiledôneas, a perfeita associação da síndrome Kranz à via fotossintética $\mathrm{C}_{4}$; na família Amaranthaceae, esta associação foi determinada nas quatro espécies do gênero Gomphrena estudadas (G. caespitosa, G. dispersa, G. nitida e G. sonorae). Johnson \& Hatch (1968) também verificaram a síndrome Kranz em G. celosioides e estabeleceram a operação da via $\mathrm{C}_{4}$ com estudos adicionais relacionados à atividade enzimática e taxas fotossintéticas. Hocking \& Anderson (1986), por meio de ensaios de fosforilação enzimática, confirmaram a via $\mathrm{C}_{4}$ em G. celosioides e G. globosa. De acordo com Press (1999), a via fotossintética $C_{4}$ é taxonomicamente incomum e largamente dispersa nas dicotiledôneas; o alto grau de convergência evolutiva não garante um único padrão em nível bioquímico ou em organização celular e subcelular.

As descrições macro e microscópicas das folhas de G. arborescens, bem como a determinação da densidade estomática e de vênulas terminais podem contribuir para a correta identificação de drogas constituídas desse órgão da planta e para o controle de qualidade do produto. De acordo com Metcalfe \& Chalk (1979), o número de vênulas terminais por milímetro quadrado de superfície foliar é considerado uma característica estatisticamente confiável para diagnóstico de fitoterápicos baseados em folhas.

Os compostos fenólicos são abundantes nas folhas de G. arborescens; entre eles, a maior distribuição é de lignina e flavonóides. Zuanazzi (1999) classificou os flavonóides como pigmentos polifenólicos diversificados que podem exercer diversas funções no vegetal. Para Harborne (1966), a classe dos flavonóis parece estar mais presente em espécies arbóreas, enquanto as flavonas e flavanonas aparecem mais em espécies herbáceas; em Amaranthaceae já foram encontradas isoflavonas, normalmente incolores. Zuanazzi (1999) relacionou as flavanonas com o sabor amargo e as flavonas e flavonóis com a co-pigmentação em flores e proteção anti-UV nas folhas.

Os flavonóides das folhas de G. arborescens merecem maiores investigações para a qualificação e quantificação, bem como para relacioná-los ou não ao uso medicinal popular das folhas contra a dismenorréia. Gros et al. (1985) relataram atividades farmacológicas 
de bioflavonóides contra fragilidade capilar, como antiescleróticos e antiedematosos, como dilatadores das coronárias e com atividades espasmolítica, fungitóxica, antihepatotóxica, colerética, estrógena, diurética e antimicrobiana.

Como a demanda e a comercialização de plantas medicinais estão intensificando, é necessário envidar esforços para ampliar o conhecimento botânico da flora do Cerrado que é consumida in natura como medicinal e o esclarecimento da real potencialidade econômica de plantas não cultivadas, especialmente as coletadas integralmente como G. arborescens. A determinação da real potencialidade fitoterápica da espécie e da eventual toxicidez devem ser efetuadas por meio de investigações fitoquímicas e farmacológicas específicas. Os testes histoquímicos realizados nas folhas podem nortear esses estudos.

A determinação do(s) princípio(s) ativo(s) das folhas e a comparação com os compostos presentes no sistema subterrâneo pode ajudar à redução da pressão sobre a espécie, evitando a coleta integral. Por outro lado, também podem incentivar a busca de alternativas para a produção comercial da espécie, em caso de comprovação de sua eficácia terapêutica.

\section{Agradecimentos}

À CAPES, pela bolsa de mestrado do primeiro Autor; ao corpo técnico do laboratório de Anatomia Vegetal da UnB, pelo apoio no desenvolvimento da pesquisa; ao Prof. MSc. Maurício Pimenta Magalhães, pela revisão crítica; à Profa. MSc. Sueli Maria Gomes, pela valiosa bibliografia.

\section{Referências bibliográficas}

Almeida, S.P.; Proença, C.E.B.; Sano, S.M. \& Ribeiro, J.F. 1998. Cerrado - espécies vegetais úteis. Planaltina, EMBRAPA.

ANVISA. 2000. Resolução RDC 17, de 24 de fevereiro de 2000. Disponível em http://e-legis.bvs.br/leisref/public. Acesso em 10/8/2004.

Arens, K. 1958. O cerrado como vegetação oligotrófica. Boletim de Botânica da Faculdade de Filosofia, Ciências e Letras da Universidade de São Paulo 15: 59-77.

Barros, M.G.A.E. 1982. Plantas medicinais - usos e tradições em Brasília, DF. Oréades 8(14/15): 140-149.

BBC. 2004. Consumo de ervas medicinais “ameaça espécies”. Disponível em http://www.bbc.co.uk/ portuguese/ciencia/story/2004/01. Acesso em 9/1/2004.

Borsch, T.; Clemants, S. \& Mosyakin, S. 2001. Symposium: Biology of the Amaranthaceae-Chenopodiaceae alliance. Journal of the Torrey Botanical Society 128(3): 234-235.
Calixto, J.B. 2001. Medicamentos fitoterápicos. Pp. 297-315. In: R.A. Yunes \& J.B. Calixto. Plantas medicinais sob a ótica da química medicinal moderna. Chapecó, Argos Ed.

Carolin, R.C.; Jacobs, S.W.L. \& Vesk, M. 1978. Kranz cells and mesophyll in the Chenopodiales. Australian Journal of Botany 26: 683-698.

Charrière-Ladreix, Y. 1976. Répartition intracellulaire du secrétat flavonique de Populus nigra L. Planta 129: 167-174.

Ehleringer, J. 1984. Ecology and ecophysiology of leaf pubescence in North Amercina desert plants. Pp. 113-131. In: E. Rodriguez; P.L. Healey \& I. Mehta (eds.). Biology and chemistry of plant trichomes. New York, Plenum Press.

Estelita-Teixeira, M.E. \& Handro, W. 1984. Leaf ultrastructure in species of Gomphrena and Pfaffia (Amaranthaceae). Canadian Journal of Botany 62: 812-817.

Furr, M. \& Mahlberg, P.G. 1981. Histochemical analysis os lacticifers and glandular trichomes in Cannabis sativa. Journal of Natural Products 44: 153-159.

Gabe, M. 1968. Techniques histologiques. Paris, Masson \& Cie.

Gros, E.G.; Pomilio, A.B.; Seldes, A.M. \& Burton, G. 1985. Introducción al estúdio de los productos naturales. Washington, Universidade de Buenos Aires/ Secretaria General de la Organización de los Estados Americanos.

Gutschick, V.P. 1999. Biotic and abiotic consequences of differences in leaf structure - research reviews. New Phytologist 143: 3-18.

Handro, W. 1964. Contribuição ao estudo da venação e anatomia foliar das amarantáceas dos cerrados. Anais da Academia Brasileira de Ciências 36(4): 479-499.

Harborne, J.B. 1966. The evolution of flavonoid pigments in plants. Pp. 271-295. In: T. Swain (ed.). Comparative phytochemistry. London, Academic Press.

Hickey, L.J. 1974. Clasificación de la arquitectura de las hojas de dicotiledoneas. Boletin de la Sociedad Argentina de Botánica 16(1-2): 1-26.

Hickey, L.J. 1979. A revised classification of the architecture of dicotyledonous leaves. Pp. 25-39. In: C.R. Metcalfe \& L. Chalk. Anatomy of the Dicotyledons - systematic anatomy of the leaf and stem. v. I., 2 ed. London, Oxford University Press.

Hocking, C.G. \& Anderson, J.W. 1986. Survey of pyruvate, phosphate dikinase activity of plants in relation to the $\mathrm{C}_{3}, \mathrm{C}_{4}$ and CAM mechanisms of $\mathrm{CO}_{2}$ assimilation. Phytochemistry 25(7): 1537-1543.

Johansen, D.A. 1940. Plant Microtechnique. London, McGraw-Hill.

Johnson, H.S. \& Hatch, M.D. 1968. Distribution of the $\mathrm{C}_{4}{ }^{-}$ dicarboxilic acid pathway of photosynthesis and its occurrence in dicotyledonous plants. Phytochemistry 7: 375-380.

Judd, W.S.; Campbell, C.S.; Kellog, E.A. \& Stevens, P.F. 1999. Plant Systematics - a phylogenetic approach. Sunderland, Sinauer Associates, Inc. 
Kraus, J.E. \& Arduin, M. 1997. Manual básico de métodos em morfologia vegetal. Rio de Janeiro, EDUR.

Laboriau, L.G.; Oliveira, J.C. \& Salgado-Laboriau, M.L. 1961. Transpiração de Schizolobium parahyba (Vell.) Toledo. I - Comportamento na estação chuvosa, nas condições de Caeté, Minas Gerais, Brasil. Anais da Academia Brasileira de Ciências 33(2): 238-257.

Laboriau, M.L.S. 1961. Pollen grain of plants of the “Cerrado" - I. Anais da Academia Brasileira de Ciências 33(1): 119-130.

Lorenzi, H. \& Matos, F.J.A. 2002. Plantas medicinais no Brasil - nativas e exóticas. Nova Odessa, Instituto Plantarum.

Mace, M.E. \& Howell, C.R. 1974. Histochemistry and identification of condensed tannin precursor in root of cotton seedlings. Canadian Journal of Botany 52: 2423-2426.

Maciel, M.A.M.; Pinto, A.C. \& Veiga Jr., V.F. 2002. Plantas medicinais: a necessidade de estudos multidisciplinares. Química Nova 25(3): 429-438.

Metcalfe, C.R. \& Chalk, L. 1979. Anatomy of the Dicotyledons - systematic anatomy of the leaf and stem. v.I. 2 ed. London, Oxford University Press.

Monteiro-Scanavacca, W.R. 1971. Vascularização floral em Amaranthaceae. Ciência e Cultura 23(3): 339-349.

Mott, K.A.; Gibson, A.C. \& O’Leary, J.W. 1982. The adaptive significance of amphistomatic leaves. Plant, Cell and Environment 5: 455-460.

Parkhust, D.F. 1978. The adaptive significance of stomatal occurrence on one or both surfaces of leaves. Journal of Ecology 66: 367-383.

Paula, J.E. \& Alves, J.L.H. 1997. Madeiras Nativas anatomia, dendrologia, dendrometria, produção e uso. Brasília, Fundação MOA (Mokiti Okada).

Pio Corrêa, M. 1984. Dicionário de plantas úteis do Brasil e das exóticas cultivadas. v.V, p. 523. Brasília, Ministério da Agricultura/IBDF.

Press, M.C. 1999. The funcional significance of leaf structure: a search for generalizations - research revies. New Phytologist 143: 213-219.

Proença, C.; Oliveira, R.S. \& Silva, A.P. 2000. Flores e Frutos do Cerrado. São Paulo, Ed. da UNB, Brasília/Imprensa Oficial do Estado.
Rosito, C.M.; Erlich, D.; Nakagawa, M. \& Zelnik, R. 1971. Fitoquímica anti-neoplásica: I - triagem de algumas espécies vegetais nos testes de inibição do carcinoma de Ehrlich. Anais da Academia Brasileira de Ciências 43(3/4): 687-689.

Salles, A.E.H. \& Lima, C.G. 1990. Flores dos Cerrados Pequeno Guia. Brasília, GDF.

Silva, J.B.; Salatino, A. \& Panizza, S. 1976. Ensaios fitoquímicos preliminares em espécies do Cerrado. Boletim Botânico da Universidade de São Paulo 4: 129-132.

Siqueira, J.C. 1984. O gênero Gomphrena L. (Amaranthaceae) nos cerrados do Brasil. Acta Biologica Leopoldinensia 6(2): 183-194.

Siqueira, J.C. 1987. Importância alimentícia e medicinal das amarantáceas do Brasil. Acta Biologica Leopoldinensia 9(1): 99-110.

Siqueira, J.C. 1992. O gênero Gomphrena L. (Amaranthaceae) no Brasil. Pesquisas - Botânica 43: 5-197.

Siqueira, J.C. 2002. Amaranthaceae. Pp. 11-30. In: M.G.L. Wanderley; G.J. Shepherd; A.M. Giulietti; T.S. Melhem; V. Dittrich \& C. Kameyama (eds.). Flora fanerogâmica do Estado de São Paulo. v.II. São Paulo, Hucitec.

Theobald, W.L.; Krahulik, J.L. \& Rollins, R.C. 1979. Trichome description and classification. Pp. 40-53. In: C.R. Metcalfe \& L. Chalk (eds.). Anatomy of the Dicotyledons - systematic anatomy of the leaf and stem. v.I. 2 ed. London, Oxford University Press.

Welkie, G.W. \& Caldwell, M. 1970. Leaf anatomy of species in some dicotyledon families as related to the $\mathrm{C}_{3}$ e $\mathrm{C}_{4}$ pathways of carbon fixation. Canadian Journal of Botany 48: 2135-2146.

Wilkinson, H.P. 1979. The plant surface (mainly leaf). Part I: stomata. Pp. 97-117. In: C.R. Metcalfe \& L. Chalk. Anatomy of the Dicotyledons - systematic anatomy of the leaf and stem. v.I. 2 ed. London, Oxford University Press.

Zuanazzi, J.A.S. 2001. Flavonóides. Pp. 499-526. In: C.M.O. Simões; E.P. Schenkel; G. Gosmann; J.C.P. Mello; L.A. Mentz \& P.R. Petrovick (eds.). Farmacognosia - da planta ao medicamento. 3 ed. Porto Alegre, Ed. UFRGS/ Florianópolis, Ed. da UFSC. 